\title{
Cellular phagocytic studies in rheumatoid arthritis patients treated with levamisole
}

\author{
KATHERINE M. WYNNE, P. A. DIEPPE, JANE SCOTT, AND \\ E. C. HUSKISSON \\ From the Department of Rheumatology and Experimental Pathology, St Bartholomew's Hospital, \\ London ECIA $7 B E$
}

SUMMARY A simple method is described which allows sequential monitoring of the endocytic activity of blood and synovial fluid cells from rheumatoid arthritis patients undergoing therapy with levamisole. Evidence of immediate (24 hour) and long-term (5-7 weeks) cellular phagocytic enhancement is presented.

Endocytosis is a property common to both polymorphonuclear leucocytes and mononuclear phagocytes-cells which are known to play a central and critical role in acute and chronic inflammation respectively ${ }^{1}$ and hence also in acute exacerbations of the underlying chronic disease process in rheumatoid arthritis (RA). Rheumatoid synovial aspirates represent one of the relatively few sources of such human inflammatory cells amenable to direct study (i.e., without resort to prior disaggregation techniques) and have the additional advantage that they offer the possibility of sequential sampling with minimal invasive trauma. However, the design of appropriate techniques for the subsequent isolation and functional characterisation of these cells has to be sufficiently flexible to accommodate extensive individual variation in terms of sample yield and cellularity. Concomitant blood samples, processed in parallel, permit comparison of local and systemic cellular endocytic capacity during the course of inflammatory disease progression and/or response to therapy.

Levamisole has been shown to be effective in the treatment of $\mathbf{R A}^{2}$ and is thought to be capable of exerting an influence upon various fundamental aspects of the cell-mediated immune process, including endocytosis. ${ }^{3}$ The present report describes a pilot study initiated to investigate the endocytic activity of cells isolated from the blood and synovial exudates of patients with RA undergoing therapy with levamisole.

Accepted for publication 30 September 1980 .

Correspondence to Dr K. M. Wynne, Immunology Division, Paterson Laboratories, Christie Hospital and Holt Radium Institute, Manchester M20 9BX.

\section{Materials and methods}

PATIENTS AND CONTROLS

Before starting levamisole treatment patients with definite or classical RA by the American Rheumatism Association's criteria ${ }^{4}$ were stabilised on an optimal anti-inflammatory regimen which was maintained throughout the course of the studies.

Short-term study. Twelve RA patients and 12 ageand sex-matched controls (11 nonrheumatoid patients and 1 normal healthy donor) received $150 \mathrm{mg}$ levamisole over a 24-hour period.

Long-term study. Fifteen RA patients received either continuous $(150 \mathrm{mg} /$ day $)$ or intermittent $(150 \mathrm{mg} /$ day on 3 consecutive days/week) levamisole therapy as part of a double-blind trial of drugtreatment schedules reported previously. ${ }^{5}$ Retrospective analysis revealed that random allocation had resulted in 8 patients in the continuous, and 7 in the intermittent, treatment groups respectively. Five RA patients receiving anti-inflammatory but not levamisole therapy served as controls.

Clinical assessment. Clinical measurements made included pain, ${ }^{6}$ duration of morning stiffness, articular index, ${ }^{7}$ joint size, ${ }^{8}$ erythrocyte sedimentation rate, complement (C3), immunoglobulins (IgG, $\operatorname{IgA}$, and $\operatorname{IgM}$ ), latex test for rheumatoid factor, and antinuclear factor. Assessments were made at $0,3,6,9,12$, and 18 months.

\section{BLOOD AND SYNOVIAL FLUID SAMPLES}

Paired blood samples were obtained from all patients and controls, and in addition paired synovial fluid samples were obtained from 5 patients in the long-term study (4 in the continuous and 1 in 
the intermittent treatment groups respectively) who presented with effusions. Samples were taken immediately before the beginning of levamisole treatment and at the appropriate interval thereafter, i.e., 24 hours (short-term study) or 5 to 7 weeks (long-term study).

Blood samples. $10 \mathrm{ml}$ blood samples were anticoagulated with $10 \mathrm{U} / \mathrm{ml}$ preservative-free heparin (Weddel Pharamaceuticals, London EC1A 9HY), the erythrocytes were sedimented at room temperature and unit gravity for 1-2 hours, and the supernatant plasma and cells collected carefully.

Synovial fluid samples. Synovial fluid was aspirated by the anteromedial route of entry into the knee joint ${ }^{9}$ under sterile precautions throughout. Amounts obtained varied between 2 and $20 \mathrm{ml}$, and heparin was added immediately to give a final concentration of $10 \mathrm{U} / \mathrm{ml}$. Synovial aspirates were processed in parallel with the cell rich plasma from the corresponding blood sample.

\section{SAMPLE PREPARATION AND}

PHAGOCYTIC ASSAY

Slide chamber preparation. Triplicate microwells were constructed by using beeswax to cement $14 \mathrm{~mm}$ diameter plastic rings (Millipore UK, London NW10 7SP) on to glass microscope slides precoated with Formvar resin (Polaron, London N3 1XH).

Sample preparation. All preincubation sample manipulations were conducted at $4^{\circ} \mathrm{C}$. Each sample of either synovial aspirate or cell rich plasma was divided into 2 , one portion being centrifuged at $3000 \mathrm{~g}$ for 15 minutes to remove the cells, while a cell count was performed on the remainder. Then the leucocyte concentration in the uncentrifuged portion was adjusted to an arbitrary value of $2.5 \times 10^{6} / \mathrm{ml}$ by diluting with cell free autologous synovial fluid or plasma as appropriate. $2 \mathrm{ml}$ of the standardised cell suspension were diluted 1:1 with ice-cold medium 199 (Flow Laboratories, Irvine KA12 8NB) containing antibiotics (penicillin $100 \mathrm{U} / \mathrm{ml}$ and streptomycin $100 \mu \mathrm{g} / \mathrm{ml}$-Glaxo Laboratories, Greenford UB6 0HE) and heparin $(10 \mathrm{U} / \mathrm{ml})$, and a $0.1 \mathrm{ml}$ aliquot of a $1 / 200$ dilution of polystyrene latex particles (Dow 1.01 $\mu \mathrm{m}$ diameter-Micro-Bio Laboratories, London SW6 3DX) in phosphatebuffered saline (PBS) was added to give a particle: cell ratio of approximately 10:1. After thorough mixing, the suspension was seeded into slide chambers in a random fashion, sealed with Mylar film (Becton-Dickenson UK, Wembley HA9 0PS) and incubated for $1-4$ hours at $37^{\circ} \mathrm{C}$ to allow the cells to phagocytose the latex particles (LP) and attach to the substrate.

Phagocytic assay. After the appropriate incubation time the Mylar film was removed, the microwells were rinsed thoroughly with warm PBS to remove unattached cells and LP, and the adherent cell monolayers were fixed in Bouin's fluid and stained with either haematoxylin or Giemsa. Then the plastic rings were removed, and coverslip preparations were made and examined under a 'Universal' microscope and an oil immersion $\times 100$ objective (Zeiss (Oberkochen), London W1P 8AP). Cells were classified on morphological grounds as either, mononuclear (MN) or polymorphonuclear (PMN), and scored for presence or absence of LP. A minimum of 500 cells per well, i.e., 1500 cells per triplicate determination, were scored. On occasions individual particle counts were performed to determine the phagocytic index, i.e., the mean number of LP per cell. The term phagocytic capacity was used to describe the proportion of cells showing phagocytic activity in a particular population, i.e., the \% cellular uptake of LP. The figures for phagocytic 'shift' were derived as follows: post-treatment phagocytic capacity value minus pretreatment phagocytic capacity value equals phagocytic 'shift' value for a particular individual. Mean 'shift' values (and standard deviations) for each group of patients were calculated from the constituent individual values in the normal manner.

STATISTICAL METHODS

Phagocytic capacity. A Hewlett-Packard System 45 Desktop Computer was used to perform chi-square analyses on enumeration data; a p value of 0.045 or less (see Table 2) was considered to be significant. Phagocytic 'shift' values were compared by Student's $t$ test. Correlation coefficients were determined by the Spearman rank test.

\section{Results}

\section{MONOLAYER PREPARATION AND}

REPRODUCIBILITY OF THE PHAGOCYTIC ASSAY The use of Formvar as substrate proved crucial to the preparation of adherent monolayers of well-spread cells (Fig. 1) from unwashed suspensions of blood and synovial fluid leucocytes. Conventional glass and tissue-culture-treated plastics were found to be unsuitable for this particular application, since the cells failed to adhere firmly to these surfaces during the relatively short (1-4 hour) in-vitro incubation periods employed in the present study. Analysis of the cellular composition of monolayers prepared on Formvar substrates revealed that the mean $M N$ component remained relatively constant in the case of those obtained from blood, but evidenced a slight post-treatment increase in the case of those obtained from synovial fluid (Table 1). 

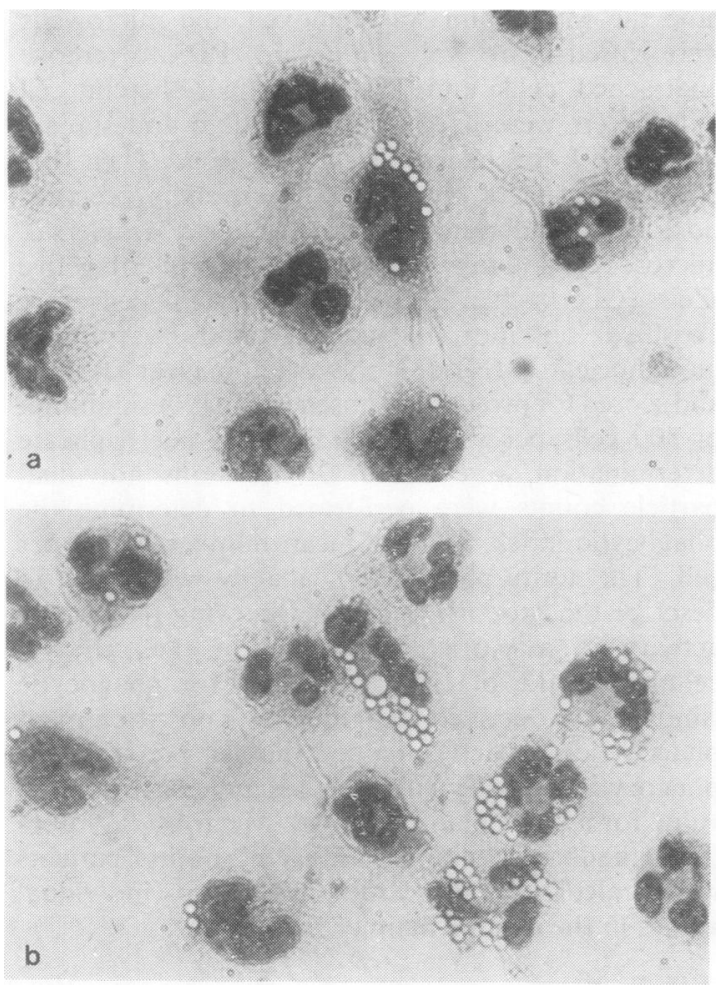

Figs. 1a and b Monolayer preparations of blood cells incubated with latex particles for 4 hours in vitro. The predominantly perinuclear arrangement of the latex particles is indicative of actual endocytosis rather than nonspecific surface adsorption, an observation which can be confirmed at the scanning electron microscope level. (Haenatoxylin, $\times$ 540).

Table 1 MN component of monolayers prepared on Formvar-coated glass

\begin{tabular}{|c|c|c|c|}
\hline & & Pretreatment & Posttreatment \\
\hline $\begin{array}{l}\text { Whole patient } \\
\text { group }(n=15)\end{array}$ & Blood & $\begin{array}{l}12 \cdot 73 \% \\
(6 \cdot 88) \\
\text { Range: } \\
4 \cdot 50-31 \cdot 31 \%\end{array}$ & $\begin{array}{l}12 \cdot 18 \% \\
(4 \cdot 21) \\
\text { Range: } \\
4 \cdot 80-23 \cdot 04 \%\end{array}$ \\
\hline $\begin{array}{l}\text { Patients presenting } \\
\text { with effusions } \\
(n=5)\end{array}$ & $\begin{array}{l}\text { Blood } \\
\text { Synovial } \\
\text { fluid }\end{array}$ & $\begin{array}{l}13 \cdot 22 \% \\
(10 \cdot 20) \\
\text { Range: } \\
6 \cdot 69-31 \cdot 31 \% \\
19 \cdot 81 \% \\
(18 \cdot 61) \\
\text { Range: } \\
3 \cdot 60-44.68 \%\end{array}$ & $\begin{array}{l}13 \cdot 20 \% \\
(5 \cdot 85) \\
\text { Range: } \\
8 \cdot 38-23 \cdot 04 \% \\
27 \cdot 32 \% \\
(26 \cdot 62) \\
\text { Range: } \\
5 \cdot 02-70 \cdot 20 \%\end{array}$ \\
\hline
\end{tabular}

*6-8 weeks' levamisole therapy. Mean values ( \pm standard deviations) are derived from triplicate determinations involving a total of 1500 cells.

Table 2 gives the values obtained for percentage cellular uptake of LP when blood cells from 2 individual donors were tested on 3 consecutive days,
Table 2 Three-day determination of blood cell phagocytic capacity

\begin{tabular}{rllll}
\hline & Donor $A$ & \multicolumn{3}{c}{ Donor B } \\
\cline { 2 - 5 } & $M N$ & $P M N$ & $M N$ & $P M N$ \\
\hline Day 1 & $77.04 \%$ & $59.73 \%$ & $74.66 \%$ & $45.78 \%$ \\
& $(5.97)$ & $(2.64)$ & $(7.17)$ & $(0.73)$ \\
2 & $76.75 \%$ & $56.25 \%$ & $71.73 \%$ & $42.58 \%$ \\
& $(3.00)$ & $(4.66)$ & $(6.22)$ & $(2.84)$ \\
3 & $86.22 \%$ & $55.04 \%$ & $77.85 \%$ & $47.10 \%$ \\
& $(4.78)$ & $(2.09)$ & $(6.85)$ & $(3.85)$ \\
p value & 0.1618 & 0.0459 & 0.2625 & 0.0506 \\
\hline
\end{tabular}

Figures represent the \% cellular uptake of latex particles after 4 hours' incubation in vitro. Mean ( \pm SD) derived from triplicate determinations involving a total of 1500 cells. $p$ Values derived from chi-square tests on original numbers of cells scored in each group.

and illustrates the degree of reproducibility of the phagocytic assay technique employed.

\section{EFFECT OF SHORT-TERM LEVAMISOLE \\ TREATMENT}

Determination of blood cell endocytic capacity in 12 RA patients and 12 controls prior to the initiation of short-term levamisole therapy revealed that there was no difference $(p>0 \cdot 1)$ in pretreatment phagocytic performance between the 2 groups. After 2 hours' incubation in vitro the mean values obtained for percentage cellular uptake of LP were $40 \cdot 40 \pm$ $12.63 \%(\mathrm{MN})$ and $22.03 \pm 15.51 \%(\mathrm{PMN})$ for the RA patients, and $36.48 \pm 16.32 \%(\mathrm{MN})$ and $20 \cdot 22 \pm 11 \cdot 40 \%$ (PMN) for the controls. There was thus no evidence of suboptimal or depressed phagocytic capacity in the rheumatoid group.

Short-term levamisole therapy of 24 hours' duration was found to have a detectable effect on blood cell function peculiar to each group (Table 3). In the rheumatoid group phagocytic capacity was significantly increased in approximately one-half of the patients $(5 / 12$, i.e., $42 \%$ in the $M N$, and $6 / 12$, i.e., $50 \%$ in the PMN categories respectively) and the overall phagocytic 'shift' values (mean alterations in

Table 3 Alterations in the phagocytic capacity of blood cells from $R A$ patients and controls undergoing short-term (24-hour) treatment with levamisole

\begin{tabular}{|c|c|c|c|c|c|c|c|c|}
\hline & \multicolumn{4}{|c|}{$M N$} & \multicolumn{4}{|c|}{$P M N$} \\
\hline & \multicolumn{3}{|c|}{$\begin{array}{l}\text { Phagocytic } \\
\text { capacity }\end{array}$} & \multirow[t]{2}{*}{$\begin{array}{l}\text { Phagocytic } \\
\text { 'shift' }\end{array}$} & \multicolumn{3}{|c|}{$\begin{array}{l}\text { Phagocytic } \\
\text { capacity }\end{array}$} & \multirow[t]{2}{*}{$\begin{array}{l}\text { Phagocytic } \\
\text { 'shift' }\end{array}$} \\
\hline & + & 0 & - & & + & 0 & - & \\
\hline $\begin{array}{l}\text { RA patients } \\
(\mathrm{n}=12)\end{array}$ & 5 & 7 & 0 & $\begin{array}{l}+5.00 \% \\
(11.44)\end{array}$ & 6 & 5 & 1 & $\begin{array}{l}+6.48 \% \\
(10.97)\end{array}$ \\
\hline $\begin{array}{l}\text { Controls } \\
(n=12)\end{array}$ & 1 & 8 & 3 & $\begin{array}{l}-3.20 \% \\
(7.56) \\
p=0.05\end{array}$ & 0 & 6 & 6 & $\begin{array}{l}-4.35 \% \\
(5.02) \\
p<0.01\end{array}$ \\
\hline
\end{tabular}

$+=$ Significantly increased. $-=$ Significantly decreased. $0=$ unchanged. Phagocytic 'shift': mean change in proportion of phagocytic cells after treatment $( \pm$ SD) - - see 'Materials and Methods'. 
the proportions of phagocytic cells calculated from the pre- and post-treatment data obtained for all 12 patients-see 'Materials and methods') were positive. In the control group, however, a significant decrease in phagocytic capacity was observed in $25 \%$ $(\mathrm{MN})-50 \%(\mathrm{PMN})$ of the individuals tested, and the overall phagocytic 'shift' values were negative. These differences between the RA and control groups were found to be significant at the $5 \%(\mathrm{MN})$ and $1 \%(P M N)$ levels.

\section{EFFECT OF LONG-TERM LEVAMISOLE TREATMENT}

A control group of 5 RA patients receiving antiinflammatory therapy alone failed to show any significant alteration $(P>0 \cdot 1)$ in cellular phagocytic capacity when tested at 0 and 5-7 weeks respectively.

Levamisole therapy of 5-7 weeks' duration, however, was found to have a pronounced effect on cellular phagocytic capacity. Fig. 2 shows the preand post-treatment values obtained for LP uptake by blood MN and PMN cells from a single patient, and it can be seen that there was evidence of substantial phagocytic enhancement after 6 weeks' treatment with levamisole. Both cell populations showed increases not only in their proportion of phagocytic cells (mean phagocytic 'shift': $M N+34 \cdot 84 \%$ and PMN $+43.83 \%$ ), but also in their respective phagocytic indices, i.e., average particle loads per cell (mean changes: $\mathrm{MN}+1.47$ and $\mathrm{PMN}+0.88$ ).

The results obtained for the whole group of 15 patients are summarised in Table 4 . From this it can

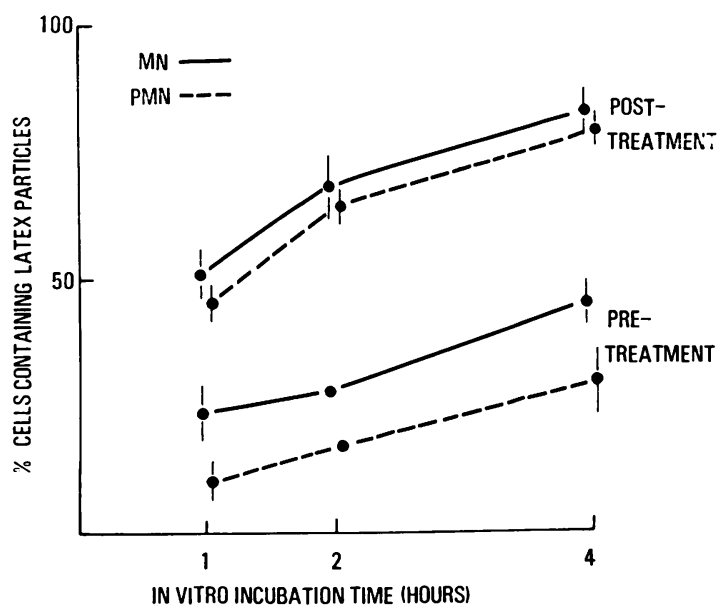

Fig. 2 Effect of 6 weeks' levamisole therapy on the \% cellular uptake of LP by blood MN and PMN from a single patient. Mean values (and $S D$ ) are derived from trip!icate determinations involving a total of 1500 cells.
Table 4 Alterations in the phagocytic capacity of blood and synovial fluid cells from patients undergoing longterm treatment with levamisole

$\frac{M N}{\text { Phagocytic Phagocytic Phagocytic Phagocytic }}$
$\begin{aligned} & \text { capacity 'shift' } \\ & +0-1\end{aligned}$

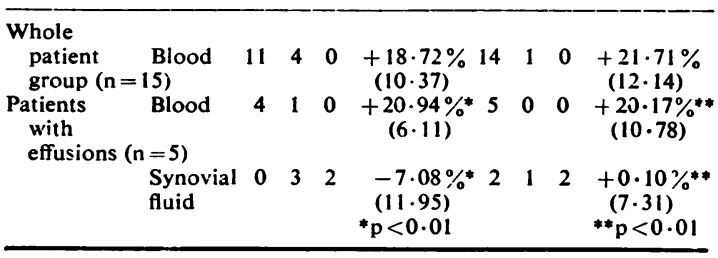

$+=$ Significantly increased. $-=$ Significantly decreased. $0=$ Unchanged. Phagocytic 'shift': mean change in proportion of phagocytic cells after treatment ( \pm SD) - see 'Mtaterials and methods'. *!**Blood and synovial fluid phagocytic 'shift' values were compared by Students' $t$ test.

be seen that after levamisole therapy MN blood cell phagocytic capacity was significantly increased in $11 / 15$ patients $(73 \%)$, and the corresponding figure for PMN cells was $14 / 15(93 \%)$, i.e., nearly all the patients in this instance. Phagocytic 'shift' values were $+18 \cdot 72 \%$ and $+21.71 \%$ for the $\mathrm{MN}$ and PMN cell categories respectively. In addition it was found that blood cell activity patterns in the subgroup of 5 patients presenting with effusions accurately reflected those exhibited by the group as a whole. By way of contrast, however, the effect of levamisole treatment on synovial fluid cells was much less pronounced. Evidence of PMN phagocytic stimulation in $2 / 5$ patients was offset by significant phagocytic depression in both cell groups, and overall the proportions of phagocytic cells remained either unchanged (PMN $+0 \cdot 10 \%)$ or slightly depressed (MN $-7 \cdot 08 \%$ ). Statistical comparison of the phagocytic 'shift' values obtained for blood and synovial fluid cells in these 5 patients revealed significant differences in both the MN and PMN categories $(p<0 \cdot 01)$.

Retrospective comparison of patients receiving continuous $(8 / 15)$ versus intermittent $(7 / 15)$ levamisole treatment revealed essentially no difference $(p>0 \cdot 1)$ between the patterns of blood cell activity obtained in either group (Table 5). No conclusions could be drawn as to the effect of different treatment regimens on synovial fluid cell activity, owing to the relatively small numbers of patients involved and their unequal distribution between the 2 treatment groups.

CORRELATION WITH CLINICAL FEATURES Pretreatment PMN phagocytic levels correlated 
Table 5 Alterations in the phagocytic capacity of blood and synovial fuid cells from patients undergoing long-term treatment with levamisole (continuous vs intermittent regimens)

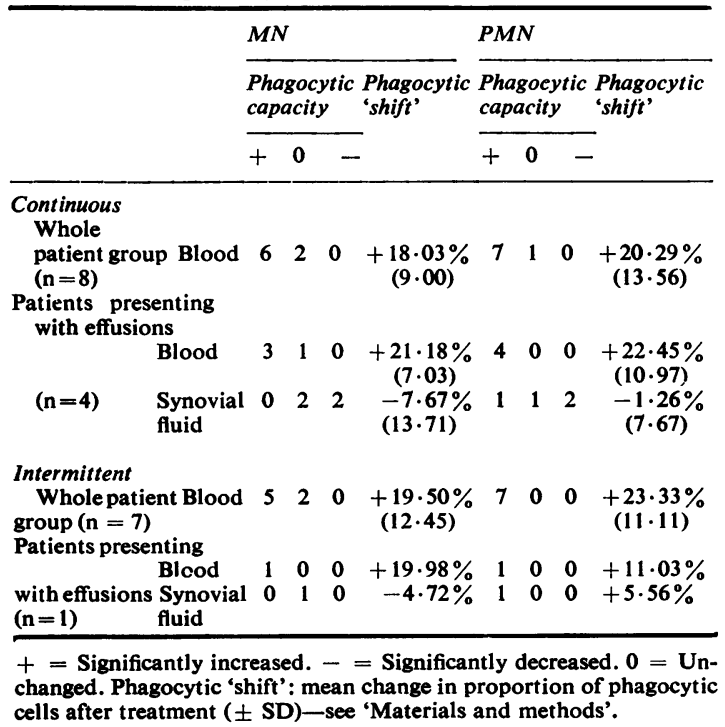

positively with initial $E S R$ values $(R=0.454$, $\mathrm{p}<0.05)$ and $\operatorname{IgM}(\mathrm{R}=0.464, \mathrm{p}<0.05)$ and correlated negatively $(R=-0.445, p<0.05)$ with the duration of disease measured in years. No such correlation was apparent in the corresponding $\mathrm{MN}$ group. Phagocytic 'shift' values at 6 weeks failed to show any correlation with clinical response to therapy assessed over an 18-month period.

\section{Discussion}

The phagocytic assay employed in the present study was designed to enable qualitative (i.e., MN/PMN ratio) and semi-quantitative (i.e., phagocytic capacity) data to be obtained from restricted and sometimes highly variable numbers of cells, and in addition it combined the advantages of simplicity and reproducibility. However, a major limitation lay in its inability to allow separation and individual analysis of the humoral and cellular components of blood and synovial fluid.

Nevertheless, a number of points of interest were found to emerge from this pilot study. For example, blood cell phagocytic capacity appeared to be increased significantly in the majority of RA patients undergoing long-term therapy with levamisole. A proportion of patients showed evidence of cellular phagocytic stimulation as early as $\mathbf{2 4}$ hours after the initiation of levamisole treatment, an effect which was not found in the appropriate control group. In addition, there was considerable disparity between the long-term results obtained for blood and synovial fluid cells in those patients presenting with effusions.

Cellular phagocytic stimulation associated with levamisole treatment could have been attributable to a direct effect of the drug on cellular function, as has been demonstrated in a number of in-vitro test systems employing human monocytes ${ }^{10} 11$ and PMN. ${ }^{12} 13$ Or, alternatively, it might have been due to an indirect effect of the drug mediated via a reduction in circulating immune complexes (IC) such as has been observed in $\mathrm{RA}^{\mathbf{1 4}}$ and systemic lupus erythematosus ${ }^{15}$ patients undergoing therapy with levamisole. Particularly in view of the fact that IC are known to be capable of depleting complement levels ${ }^{1617}$ and of inducing phagocytic blockage ${ }^{1819}$ under appropriate circumstances. The failure of synovial fluid cells to respond to long-term levamisole therapy might have been caused by the cells becoming refractory to drug stimulation upon entering an inflammatory site or, alternatively, could have been indicative of local persistence of inhibitory IC in the inflamed joint. A further possibility is that the observable discrepancies were the result of a methodological artefact such as might have occurred had there been a consistent increase in synovial fluid viscosity on levamisole therapy and hence a possible reduction of contact between the LP and cells in the phagocytic test system employed.

Overall, the patterns of cellular activity which emerged were somewhat conflicting and difficult to interpret. For example, in the long-term study initial PMN phagocytic capacity appeared to show some correlation with disease state (notably with respect to its previous duration and concomitant clinical values for ESR and IgM). No such association was found in the corresponding $\mathrm{MN}$ cell group, and, more importantly perhaps, no difference in initial phagocytic capacity was apparent between RA patients and controls in the short-term study. However, in the latter case there was a marked difference in response to 24-hour levamisole therapy and the positive trend in the RA group was upheld on prolonged (5-7 weeks) levamisole treatment, though no correlation with clinical improvement was found.

Clearly the role of the phagocytic cell in RA merits further attention. Evaluation and comparison of the influence on this particular cell type of a number of other antirheumatic drugs in addition to levamisole could lead to a better understanding of the overall mode of action of these drugs and ultimately to the isolation of subsets within RA in which the 
stimulation or suppression of phagocytic activity might prove to be of therapeutic benefit.

The authors are indebted to Dr M. K. Palmer and Dr R. Swindell for statistical and computing advice.

\section{References}

1 Allison A C, Davies P. In: Velo G P, Willoughby D A, Giroud J P, eds. Future Trends in Inflammation. Padua and London: Piccin, 1974 ; 449-80.

2 Multicentre Study Group. Levamisole in rheumatoid arthritis. A randomised double-blind study comparing two dosage regimens of levamisole with placebo. Lancet 1978; ii: $1007-12$.

3 Symoens J, Rosenthal M. A review. Levamisole in the modulation of the immune response: the current experimental and clinical state. J Reticuloendothel Soc 1977; 21 : 175-221.

4 Committee of the American Rheumatism Association. Diagnostic criteria for rheumatoid arthritis, 1958 revision. Ann Rheum Dis 1959; 18: 49-53.

5 Scott J, Dieppe P A, Huskisson E C. Continuous and intermittent levamisole. A controlled trial. Ann Rheum Dis 1978; 37: 259-61.

- Scott J, Huskisson E C. Graphic representation of pain. Pain 1976; 2: 175-84.

7 Ritchie D M, Boyle J A, McInnes J M, et al. Clinical studies with an articular index for the assessment of joint tenderness in patients with rheumatoid arthritis. $Q J$ Med 1968; 37: 393-406.

8 Boardman P L, Hart F D. Clinical measurement of the anti-inflammatory effects of salicylates in rheumatoid arthritis. $B r$ Med J 1967; iv: 264-8.

9 Cawley M I D. Arthrocentesis: techniques and indications. Br J Hosp Med 1974; 11 : 744-56.

${ }^{10}$ Schmidt M E, Douglas S D. Effects of levamisole on human monocyte function and immunoprotein receptors. Clin Immunol Immunopathol 1976; 6: 299-305.

11 Al-Ibrahim M S, Holzman R S, Lawrence H S. Concentrations of levamisole required for enhanced proliferation of human lymphocytes and phagocytosis by macrophages. $J$ Infect Dis 1977; 135: 517-23.

12 Molin L, Stendahl O. Enhancing effect of levamisole on the phagocytic activity of human neutrophil polymorphonuclear leucocytes in vitro. Scand J Haematol 1977; 19: 93-8.

13 Repine J E, Douglas S D. Effect of levamisole on morphology, bactericidal activity, and metabolism of human neutrophils in vitro. Proc Soc Exp Biol Med 1977; 156: $527-30$.

14 Rosenthal M, Graf U, Müller W. Der Effekt der Therapie auf Immunkomplexe bei der chronischen Polyarthritis. Dsch Med Wochenschr 1977; 102: 415-8.

15 Kavai M, Lukacs K, Sonkoly I, Paloczi K, Szegedi G. Circulating immune complexes and monocyte $\mathrm{Fc}$ function in autoimmune diseases. Ann Rheum Dis 1979; 38: 79-83.

16 Zubler R H, Nydegger U, Perrin L H, et al. Circulating and intra-articular immune complexes in patients with rheumatoid arthritis. Correlation of ${ }^{125} \mathrm{I}-\mathrm{Clq}$ binding activity with clinical and biological features of the disease. J Clin Invest 1976; 57: 1308-19.

17 Nydegger U E, Zubler R H, Gabay R, et al. Circulating complement breakdown products in patients with rheumatoid arthritis. Correlation between plasma C3d, circulating immune complexes, and clinical activity. $J$ Clin Invest 1977; 59: 862-8.

18 Onyewotu I I, Holborow E J, Johnson G D. Detection and radioassay of soluble circulating immune complexes using guinea pig peritoneal exudate cells. Nature 1974; 248: 156-9.

19 Rabinovitch M, Manejias R E, Nussenzweig V. Selective phagocytic paralysis induced by immobilized immune complexes. J Exp Med 1975; 142: 827-38. 